\title{
Quadriceps muscle strength, radiographic knee osteoarthritis and knee pain: the ROAD study
}

\author{
Shigeyuki Muraki ${ }^{1 *}$, Toru Akune ${ }^{2}$, Masatoshi Teraguchi ${ }^{3}$, Ryohei Kagotani ${ }^{3}$, Yoshiki Asai ${ }^{3}$, Munehito Yoshida ${ }^{3}$, \\ Fumiaki Tokimura ${ }^{4}$, Sakae Tanaka ${ }^{5}$, Hiroyuki Oka ${ }^{6}$, Hiroshi Kawaguchi ${ }^{7}$, Kozo Nakamura $^{2}$ and Noriko Yoshimura ${ }^{8}$
}

\begin{abstract}
Background: The objective of this study was to clarify the association of quadriceps muscle strength with knee pain using a large-scale, population-based cohort of the Research on Osteoarthritis/osteoporosis Against Disability (ROAD) study.

Methods: From the 2566 subjects at the third visit of the ROAD study, the present study analyzed 2152 subjects who completed radiographic examinations and measurements of muscle strength and mass (690 men and 1462 women; mean age, $71.6 \pm 12.2$ years). Knee pain was assessed by an experienced orthopedist. Knee osteoarthritis $(\mathrm{OA})$ was defined according to Kellgren-Lawrence $(\mathrm{KL})$ grade. Quadriceps muscle strength and muscle mass at the lower limbs were measured by the Quadriceps Training Machine (QTM-05F, Alcare Co., Ltd. Tokyo, Japan) and the Body Composition Analyzer MC-190 (Tanita Corp., Tokyo, Japan), respectively.

Results: Quadriceps muscle strength and weight bearing index (WBI: quadriceps muscle strength by weight) were significantly associated with knee pain after adjustment for age and body mass index, whereas grip strength and muscle mass at the lower limbs were not. The significant association of quadriceps muscle strength with knee pain was independent of radiographic knee OA.
\end{abstract}

Conclusion: The present cross-sectional study showed an independent association of quadriceps muscle strength with knee pain.

Keywords: Cohort study, Epidemiology, Osteoarthritis, Pain, Muscle

\section{Background}

Knee osteoarthritis $(\mathrm{OA})$ is a major public health issue that causes chronic pain and disability [1-3]. The prevalence of radiographic knee OA is high in Japan [4], with 25,300,000 persons aged 40 and older estimated to have radiographic knee OA [5]. According to the recent National Livelihood Survey of the Ministry of Health, Labour and Welfare in Japan, OA is ranked fourth among diseases that cause disabilities that subsequently require support with activities of daily living [6]. The principal clinical symptom of knee OA is knee pain [7]. Although much effort has been devoted toward a definition of knee pain, its correlation with radiographic severity of knee OA is not as strong as one would expect $[4,8-10]$. In fact, our

\footnotetext{
* Correspondence: murakis-ort@h.u-tokyo.ac.jp

'Department of Clinical Motor System Medicine, 22nd Century Medical \& Research Center, Faculty of Medicine, the University of Tokyo, Hongo 7-3-1, Bunkyo-ku, Tokyo 113-8655, Japan

Full list of author information is available at the end of the article
}

previous study showed that the odds ratio (OR) of severe knee OA defined as Kellgren-Lawrence (KL) grade 3 or 4 for knee pain was 8.6 in men and 4.4 in women [4], which was significant, but the OR was not as high as expected. In addition, $10 \%$ of men without radiographic knee OA and $20 \%$ of women without radiographic knee OA had knee pain [4]. This indicates that at least $10 \%$ and $20 \%$ of knee pain in men and women, respectively, may be explained by factors other than radiographic changes.

One of the factors contributing to knee pain other than radiographic knee OA may be quadriceps muscle weakness. Thus far, grip strength has been used as a useful clinical marker of sarcopenia [11], because measuring grip strength is easy. Although there is growing evidence that reduced grip strength is associated with adverse outcomes including morbidity [12], disability [13], falls [13], higher fracture rates [14], increased length of hospital stay [15], quality of life [16] and mortality [13], and grip strength is 
related to total muscle strength [17], quadriceps muscle strength may be more strongly associated with knee symptoms than grip strength. However, to the best of our knowledge, no population-based study has compared the association of knee pain with grip strength and quadriceps muscle strength because isokinetic devices such as Cybex, Biodex, and KIN-COM, which allow for the most detailed measurements regarding the quantitative evaluation of the quadriceps muscle strength, are expensive, largescale, and impossible to move. Recently, the Quadriceps Training Machine (QTM) (QTM-05F, Alcare Co., Ltd. Tokyo, Japan) was developed to measure quadriceps muscle strength more easily [18]. The QTM has higher usability compared with other devices in terms of its small size, light weight, and good portability, as well as the fact that it has good correlation with Biodex and high credibility of measurements [18]. Although measurements of muscle mass are another method to evaluate muscle, the association between muscle strength and mass has been shown to be weak [19], indicating that a distinct association with knee symptoms between quadriceps muscle strength and muscle mass at the lower limb may be found. However, there are no population-based studies that compare the association of knee pain with quadriceps muscle strength and muscle mass at the lower limbs.

The objective of this study was to clarify the association of quadriceps muscle strength and muscle mass at the lower limbs with pain at the knee among Japanese men and women in a large-scale, population-based cohort from the Research on Osteoarthritis/osteoporosis Against Disability (ROAD) study.

\section{Methods}

\section{Subjects}

The ROAD study is a nationwide prospective study designed to establish epidemiologic indices for the evaluation of clinical evidence for the development of a disease-modifying treatment for bone and joint diseases (with OA and osteoporosis as the representative bone and joint diseases). It consists of population-based cohorts in several communities in Japan. A detailed profile of the ROAD study has been reported elsewhere $[4,5,20]$, and thus, only a brief summary is provided here. To date, we have completed the creation of a baseline database including clinical and genetic information for 3040 inhabitants (1061 men and 1979 women) ranging in age from 23 to 95 years (mean, 70.3 years), who were recruited from resident registration listings in three communities: an urban region in Itabashi, Tokyo, a mountainous region in Hidakagawa, Wakayama, and a coastal region in Taiji, Wakayama. All participants provided written, informed consent, and the study was conducted with the approval of the ethics committees of the University of Tokyo and the Tokyo Metropolitan Institute of Gerontology.

The third visit of the ROAD study began in 2011 and was completed in 2013. All participants in the baseline study were invited to participate in the third visit. In addition to the former participants, inhabitants aged $\geq 60$ years in the urban area and those aged $\geq 40$ years in the mountainous and coastal areas who were willing to participate in the ROAD survey performed in 2011-2013 were also included in the third visit.

Anthropometric measurements, including height and weight, were taken, and body mass index (BMI; weight $[\mathrm{kg}] /$ height $\left.^{2}\left[\mathrm{~m}^{2}\right]\right)$ was calculated. Grip strength was measured on the right and left sides using a TOEI LIGHT handgrip dynamometer (TOEI LIGHTCO. LTD, Saitama, Japan). Isometric quadriceps muscle strength at the right and left knee was measured by the QTM one time each, and weight bearing index (WBI: quadriceps muscle strength/body weight) was calculated. Subjects carried out knee extension exercises by placing their knee joint on the QTM where specified; the load pressure applied to the QTM in the popliteal region was measured and displayed as the isometric knee extension muscle strength (quadriceps strength). The QTM has good correlation with Biodex and high credibility of measurement, and the method has been validated [18]. Lower limb muscle mass was measured by bioimpedance analysis [21-24] using the Body Composition Analyzer MC-190 (Tanita Corp., Tokyo, Japan), and muscle mass/ height $^{2}\left(\mathrm{~kg} / \mathrm{m}^{2}\right)$ was calculated. The protocol was described by Tanimoto and colleagues $[25,26]$, and the method has been validated [27].

All participants were also interviewed by wellexperienced orthopedists regarding pain in both knees, by asking: "Have you experienced right knee pain on most days in the past month, in addition to now?" and "Have you experienced left knee pain on most days in the past month, in addition to now?". Subjects who answered "yes" were defined as having knee pain.

\section{Radiographic assessment}

All participants underwent radiographic examination of both knees using an anterior-posterior view with weightbearing and foot map positioning by experienced radiological technologists. The beam was positioned parallel to the floor with no angle and aimed at the joint space. To visualize the joint space properly and to centralize the patella over the lower end of the femur, fluoroscopic guidance with an anterior-posterior X-ray beam was used, and the images were downloaded into Digital Imaging and Communication in Medicine (DICOM) format files. Knee radiographs were read without knowledge of participant clinical status by a single experienced orthopedist (S.M.) using the KL radiographic atlas for overall 
knee radiographic grades [28], and knee OA was defined as KL grade 2 or greater. To evaluate the intraobserver variability of the KL grading, 100 randomly selected radiographs of the knee were scored by the same observer more than 1 month after the first reading. One hundred other radiographs were also scored by two experienced orthopedic surgeons (S.M. \& H.O.) using the same atlas for interobserver variability. The intra- and inter-variabilities evaluated for KL grade (0-4) were confirmed by kappa analysis to be sufficient for assessment (0.86 and 0.80 , respectively).

\section{Statistical analysis}

Differences in age, height, weight, BMI, muscle strength, WBI and muscle mass between men and women and between subjects with and without pain were examined using the non-paired student $\mathrm{t}$-test. The prevalence of knee $\mathrm{OA}$ and pain was compared between men and women by the $\chi^{2}$ test. Linear regression analysis was used to determine the association of age, muscle mass at the lower limb, and grip strength with quadriceps muscle strength. Associations of age, BMI, grip strength, quadriceps muscle strength, WBI and muscle mass at the lower limbs and KL grade with knee pain were determined using multiple logistic regression analysis after adjustment for age, sex, and BMI overall, and after adjustment for age and BMI in men and women. To determine the independent association of age, BMI, gender, muscle strength, and KL grade with knee pain, multiple logistic regression analysis was used with age, BMI, gender, muscle strength, and KL grade overall, and with age, BMI, muscle strength, and KL grade in men and women, as explanatory variables. To determine the independent association of WBI with knee pain, multiple logistic regression analysis was used with age, BMI, gender, WBI and KL grade, overall, and with age, BMI, WBI and $\mathrm{KL}$ grade in men and women as explanatory variables. In addition, subjects were classified according to muscle strength $(<10 \mathrm{kgf}, \geq 10-<20 \mathrm{kgf}, \geq 20-<30$ $\mathrm{kgf}, \geq 30-<40 \mathrm{kgf}, \geq 40 \mathrm{kgf})$, and the association of muscle strength $<10 \mathrm{kgf}, \geq 10-<20 \mathrm{kgf}, \geq 20-<30 \mathrm{kgf}$, and $\geq 30-<40 \mathrm{kgf}$ with pain was determined using multiple logistic regression analysis after adjustment for age and BMI, compared with muscle strength $\geq 40$ kgf). The thresholds of muscle strength or WBI for pain were determined using ROC curve analysis. Data analyses were performed using SAS version 9.0 (SAS Institute Inc., Cary, NC).

\section{Results}

Among the 2566 subjects who participated in the third visit of the ROAD study, 2303 (89.9\%) subjects underwent X-ray examinations at the knee. A total of 32 $(1.3 \%)$ subjects who underwent total knee arthroplasty before the third visit were excluded from the study. In addition, $12(0.5 \%)$ subjects who provided incomplete questionnaires regarding pain and 37 subjects $(1.5 \%)$ who did not undergo an examination of muscle strength or muscle mass were excluded. Further, 58 subjects $(2.3 \%)$ who were younger than 40 years were excluded, leaving a total of $2152(85.1 \%)$ subjects (690 men and 1462 women). The characteristics of the 2152 participants in the present study are shown in Table 1. Muscle strength and mass were significantly higher in men than women. WBI was not significantly different between men and women. The prevalence of knee OA and knee pain was significantly higher in women than in men. Quadriceps muscle strength was significantly associated with muscle mass at the lower limbs, but the association was weak (right: correlation coefficient $=0.28$ and 0.21 in men and women, respectively, $p<00001$; left: correlation coefficient 0.34 and 0.37 in men and women, respectively, $p<00001$ ). Quadriceps muscle strength was also significantly associated with grip strength, and the association was moderate (right: correlation coefficient $=0.47$ and 0.50 in men and women, respectively, $p<00001$; left: correlation coefficient 0.50 and 0.52 in men and women, respectively, $p<00001$ ). Quadriceps muscle strength was significantly associated with age in men and women $(p<0.0001)$ (Additional file 1 : Figure S1).

Table 2 shows age, BMI, grip strength, quadriceps muscle strength, WBI and lower limb muscle mass/ height ${ }^{2}$ in subjects with and without pain. For the right knee, age, BMI, grip strength, quadriceps muscle strength and WBI were significantly different between subjects with and without pain, whereas muscle mass was not. Results were similar for the left knee. After adjustment for age and BMI, the significant association of grip strength with knee pain disappeared in men and women.

We next examined the prevalence of knee pain according to KL grade (Fig. 1). In the overall population, the prevalence of knee pain was $12.5 \%, 19.1 \%$ and $46.5 \%$ in the right knee and $10.8 \% 18.2 \%$ and $45.3 \%$ in the left knee in subjects with $\mathrm{KL}=01, \mathrm{KL}=2$ and $\mathrm{KL}=3$ or 4 , respectively. After adjustment for age, gender and BMI, $\mathrm{KL}=3$ or 4 was significantly associated with knee pain compared with $\mathrm{KL}=01$ (right knee: odds ratio [OR] 4.16, $95 \%$ confidence interval [CI] 3.10-5.61; left knee: OR 4.90, $95 \mathrm{CI} 3.63-6.64) . \mathrm{KL}=2$ at the left knee was also significantly associated with pain (OR 1.52, $95 \%$ CI 1.17-2.00), while $\mathrm{KL}=2$ at the right knee was not (OR 1.27, $95 \% \mathrm{CI}$ 0.94-1.71). The prevalence of knee pain was $9.9 \%, 10.5 \%$ and $48.9 \%$ at the right knee and $9.1 \%, 11.5$ and $42.7 \%$ at the left knee in men with $\mathrm{KL}=01, \mathrm{KL}=2$ and $\mathrm{KL}=3$ or 4 , respectively, and $14.2 \%, 21.7 \%$ and $45.8 \%$ at the right knee and $11.9 \%, 20.8 \%$ and $45.9 \%$ at the left knee in women with $\mathrm{KL}=01, \mathrm{KL}=2$ and $\mathrm{KL}=3$ or 4 , respectively. In men and women, after adjustment for age and 
Table 1 Subject characteristics

\begin{tabular}{|c|c|c|c|c|}
\hline & Overall & Men & Women & $P$ values \\
\hline N & 2152 & 690 & 1462 & \\
\hline Age, years & $71.6 \pm 12.2$ & $72.5 \pm 12.3$ & $71.2 \pm 12.1$ & 0.0164 \\
\hline Height, cm & $154.3 \pm 9.2$ & $163.1 \pm 7.1$ & $150.1 \pm 6.8$ & $<0.0001$ \\
\hline Weight, kg & $54.3 \pm 10.7$ & $61.6 \pm 11.0$ & $50.9 \pm 8.6$ & $<0.0001$ \\
\hline $\mathrm{BMl}, \mathrm{kg} / \mathrm{m}^{2}$ & $22.7 \pm 3.4$ & $23.1 \pm 3.3$ & $22.5 \pm 3.5$ & 0.0009 \\
\hline \multicolumn{5}{|l|}{ Right } \\
\hline Grip strength & $28.1 \pm 9.6$ & $37.2 \pm 9.4$ & $23.7 \pm 5.8$ & $<0.0001$ \\
\hline Quadriceps muscle strength, kgf & $28.1 \pm 11.2$ & $31.9 \pm 12.7$ & $26.2 \pm 10.0$ & $<0.0001$ \\
\hline Weight bearing index & $0.52 \pm 0.20$ & $0.52 \pm 0.20$ & $0.52 \pm 0.20$ & 0.8724 \\
\hline Lower limb muscle mass, kg & $6.3 \pm 1.6$ & $7.9 \pm 1.5$ & $5.5 \pm 0.8$ & $<0.0001$ \\
\hline Lower limb muscle mass/height ${ }^{2}, \mathrm{~kg} / \mathrm{m}^{2}$ & $2.6 \pm 0.4$ & $3.0 \pm 0.4$ & $2.4 \pm 0.3$ & $<0.0001$ \\
\hline Knee OA (\%) & 44.1 & 31 & 50.3 & $<0.0001$ \\
\hline Knee pain (\%) & 20.6 & 15.1 & 23.3 & $<0.0001$ \\
\hline \multicolumn{5}{|l|}{ Left } \\
\hline Grip strength & $26.2 \pm 9.4$ & $35.2 \pm 9.1$ & $22.0 \pm 5.9$ & $<0.0001$ \\
\hline Quadriceps muscle strength, kgf & $26.9 \pm 11.2$ & $30.6 \pm 12.6$ & $25.1 \pm 9.9$ & $<0.0001$ \\
\hline Weight bearing index & $0.50 \pm 0.20$ & $0.50 \pm 0.20$ & $0.50 \pm 0.20$ & 0.9715 \\
\hline Lower limb muscle mass, kg & $6.2 \pm 1.6$ & $7.8 \pm 1.5$ & $5.4 \pm 0.8$ & $<0.0001$ \\
\hline Lower limb muscle mass $/$ height ${ }^{2}, \mathrm{~kg} / \mathrm{m}^{2}$ & $2.6 \pm 0.4$ & $2.9 \pm 0.4$ & $2.4 \pm 0.3$ & $<0.0001$ \\
\hline Knee OA (\%) & 45.2 & 33 & 51 & $<0.0001$ \\
\hline Knee pain (\%) & 20 & 13.9 & 22.9 & $<0.0001$ \\
\hline
\end{tabular}

Except where indicated otherwise, values are means \pm SD

Knee OA was defined as Kellgren-Lawrence grade 2 or worse

Weight bearing index was calculated as quadriceps muscle strength by weight

Differences between men and women were determined by non-paired student $t$ test except for prevalence of knee OA and knee pain

Differences in prevalence of knee OA and knee pain between men and women were determined by chi-square test

$B M I$ Body mass index, OA Osteoarthritis

BMI, $\mathrm{KL}=3$ or 4 was significantly associated with knee pain at the right knee (men: OR 6.82, $95 \%$ CI 3.94-11.9, women: OR 3.52, $95 \%$ CI 2.49-5.03) and the left knee (men: OR 5.64, 95 \% CI 3.20-9.99, women: OR 4.83, 95 \% CI 3.39-6.94). $\mathrm{KL}=2$ was not associated with knee pain except for the left knee in women (right knee, men: OR 0.91, 95 \% CI 0.45-1.73, women: 1.32, 95 \% CI 0.93-1.86; left knee, men: OR 1.08, 95 \% CI 0.56-2.00, women: 1.68 , 95 \% CI 1.16-2.45).

To determine independent associations of age, BMI, gender, muscle strength and knee $\mathrm{OA}$, we next used multiple logistic regression analysis with age, BMI, gender, quadriceps muscle strength and KL grade as explanatory variables in subjects overall, and with age, BMI, muscle strength and KL grade as explanatory variables in men and women (Table 3). Overall, BMI, gender, muscle strength and KL grade 3 or 4 were significantly associated with knee pain, whereas age and KL grade 2 were not. In men and women, BMI, muscle strength and KL grade 3 or 4 were significantly associated with knee pain. We also analyzed independent associations of age, BMI, gender, WBI and knee OA.
Results for WBI were almost the same as those for quadriceps muscle strength (overall: OR 0.85, $95 \%$ CI $0.79-0.91, p=0.0011$, men: OR $0.79,95 \%$ CI $0.69-0.90, p=0.0003$, women: OR $0.87,95 \%$ CI 0.80 $0.94, p=0.0003)$.

Next, to determine the prevalence of knee pain according to muscle strength, subjects were classified by muscle strength $(<10 \mathrm{kgf}, \geq 10-<20 \mathrm{kgf}, \geq 20-<30$ $\mathrm{kgf}, \geq 30-<40 \mathrm{kgf}, \geq 40 \mathrm{kgf})$. Prevalence of knee pain was $53.9 \%, 27.0 \%, 14.4 \%, 11.6$ and $9.8 \%$ at the right knee and $33.3 \%, 24.8 \%, 12.2 \%, 12.6 \%$ and $6.5 \%$ at the left knee in men with muscle strength $<10 \mathrm{kgf}, \geq 10-<20$ $\mathrm{kgf}, \geq 20-<30 \mathrm{kgf}, \geq 30-<40 \mathrm{kgf}$ and $\geq 40 \mathrm{kgf}$, respectively, and $41.0 \%, 31.0 \%, 23.7 \%, 16.3 \%$ and $12.5 \%$ at the right knee and $43.2 \%, 31.0 \%, 20.3 \%, 16.1 \%$ and $15.3 \%$ at the left knee in women with muscle strength $<10 \mathrm{kgf}, \geq 10-<$ $20 \mathrm{kgf}, \geq 20-<30 \mathrm{kgf}, \geq 30-<40 \mathrm{kgf}$ and $\geq 40 \mathrm{kgf}$, respectively (Fig. 2). After adjustment for age, BMI and KL grade, subjects with muscle strength $<10 \mathrm{kgf}$ and $\geq 10-<20 \mathrm{kgf}$ had a significantly higher prevalence of knee pain compared with those with muscle strength $\geq 40 \mathrm{kgf}$, except for left knee in women (Table 4). We also examined the 
Table 2 Age, BMl, grip strength and lower limb muscle strength and muscle mass in subjects with and without knee pain

\begin{tabular}{|c|c|c|c|c|c|c|c|c|c|c|}
\hline & \multicolumn{5}{|l|}{ Right knee } & \multicolumn{5}{|l|}{ Left knee } \\
\hline & Pain - & Pain + & Adjusted OR & $95 \% \mathrm{Cl}$ & $P$ values & Pain - & Pain + & Adjusted OR & $95 \% \mathrm{Cl}$ & $P$ values \\
\hline \multicolumn{11}{|l|}{ Overall } \\
\hline $\mathrm{N}$ & 1708 & 444 & & & & 1721 & 431 & & & \\
\hline Age, years & $70.8 \pm 12.5$ & $74.8 \pm 10.4^{*}$ & 1.04 & $1.03-1.035$ & $<0.0001$ & $70.8 \pm 12.5$ & $74.7 \pm 10.4^{*}$ & 1.04 & $1.03-1.05$ & $<0.0001$ \\
\hline $\mathrm{BMI}, \mathrm{kg} / \mathrm{m}^{2}$ & $22.5 \pm 3.3$ & $23.7 \pm 3.7^{*}$ & 1.13 & $1.10-1.17$ & $<0.0001$ & $22.4 \pm 3.3$ & $23.8 \pm 3.5^{*}$ & 1.14 & $1.11-1.18$ & $<0.0001$ \\
\hline Grip strength, kgf & $28.7 \pm 9.7$ & $25.5 \pm 8.5^{*}$ & 0.98 & $0.96-0.9996$ & 0.0448 & $26.9 \pm 9.5$ & $23.8 \pm 8.5^{*}$ & 0.99 & $0.97-1.01$ & 0.3464 \\
\hline $\begin{array}{l}\text { Quadriceps muscle strength, } \\
\text { kgf (5kgf increase) }\end{array}$ & $29.1 \pm 11.2$ & $23.9 \pm 10.3^{*}$ & 0.83 & $0.78-0.88$ & $<0.0001$ & $27.9 \pm 11.2$ & $22.8 \pm 10.2^{*}$ & 0.84 & $0.79-0.89$ & $<0.0001$ \\
\hline $\begin{array}{l}\text { Weight bearing index, } \mathrm{kg} / \mathrm{kg} \\
(0.1 \mathrm{kgf} / \mathrm{kg} \text { increase) }\end{array}$ & $0.54 \pm 0.20$ & $0.44 \pm 0.18^{*}$ & 0.81 & $0.76-0.86$ & $<0.0001$ & $0.52 \pm 0.19$ & $0.42 \pm 0.19^{*}$ & 0.83 & $0.77-0.88$ & $<0.0001$ \\
\hline $\begin{array}{l}\text { Lower limb muscle mass } / \text { height } \\
\mathrm{kg} / \mathrm{m}^{2}\left(0.1 \mathrm{~kg} / \mathrm{m}^{2} \text { increase }\right)\end{array}$ & $2.59 \pm 0.43$ & $2.58 \pm 0.43$ & 0.97 & $0.92-1.02$ & 0.2421 & $2.56 \pm 0.43$ & $2.56 \pm 0.42$ & 0.98 & $0.94-1.03$ & 0.4326 \\
\hline \multicolumn{11}{|l|}{ Men } \\
\hline $\mathrm{N}$ & 586 & 104 & & & & 594 & 96 & & & \\
\hline Age, years & $71.9 \pm 12.5$ & $76.1 \pm 11.0^{*}$ & 1.04 & $1.02-1.07$ & $<0.0001$ & $72.0 \pm 12.3$ & $76.1 \pm 11.7^{*}$ & 1.04 & $1.02-1.07$ & $<0.0001$ \\
\hline $\mathrm{BMI}, \mathrm{kg} / \mathrm{m}^{2}$ & $22.9 \pm 3.2$ & $23.9 \pm 3.8^{*}$ & 1.13 & $1.06-1.21$ & 0.0002 & $22.9 \pm 3.2$ & $23.9 \pm 4.0^{*}$ & 1.13 & $1.06-1.21$ & 0.0003 \\
\hline Grip strength, kgf & $37.5 \pm 9.5$ & $35.1 \pm 9.0^{*}$ & 0.98 & $0.95-1.01$ & 0.3070 & $35.5 \pm 9.0$ & $33.3 \pm 9.7^{*}$ & 0.99 & $0.96-1.02$ & 0.5031 \\
\hline $\begin{array}{l}\text { Quadriceps muscle strength, } \\
\text { kgf (5kgf increase) }\end{array}$ & $32.9 \pm 12.5$ & $26.4 \pm 12.0^{*}$ & 0.80 & $0.72-0.89$ & $<0.0001$ & $31.4 \pm 12.6$ & $25.4 \pm 11.4^{*}$ & 0.82 & $0.91-1.23$ & 0.0001 \\
\hline $\begin{array}{l}\text { Weight bearing index, } \mathrm{kgf} / \mathrm{kg} \\
(0.1 \mathrm{kgf} / \mathrm{kg} \text { increase) }\end{array}$ & $0.54 \pm 0.20$ & $0.42 \pm 0.19^{*}$ & 0.75 & $0.65-0.85$ & $<0.0001$ & $0.52 \pm 0.20$ & $0.41 \pm 0.18^{*}$ & 0.78 & $0.68-0.89$ & 0.0002 \\
\hline $\begin{array}{l}\text { Lower limb muscle } \\
\text { mass } / h_{e i g h t}{ }^{2}, \mathrm{~kg} / \mathrm{m}^{2} \\
\left(0.1 \mathrm{~kg} / \mathrm{m}^{2} \text { increase }\right)\end{array}$ & $2.95 \pm 0.44$ & $3.03 \pm 0.47$ & 1.01 & $0.92-1.10$ & 0.8897 & $2.90 \pm 0.44$ & $2.97 \pm 0.50$ & 0.98 & $0.89-1.08$ & 0.7281 \\
\hline \multicolumn{11}{|l|}{ Women } \\
\hline $\mathrm{N}$ & 1122 & 340 & & & & 1127 & 335 & & & \\
\hline Age, years & $70.2 \pm 12.5$ & $74.4 \pm 10.2^{*}$ & 1.03 & $1.02-1.05$ & $<0.0001$ & $70.2 \pm 12.6$ & $74.3 \pm 10.0^{*}$ & 1.03 & $1.02-1.05$ & $<0.0001$ \\
\hline $\mathrm{BMl}, \mathrm{kg} / \mathrm{m}^{2}$ & $22.2 \pm 3.3$ & $23.7 \pm 3.6^{*}$ & 1.13 & $1.09-1.18$ & $<0.0001$ & $22.2 \pm 3.4$ & $23.8 \pm 3.4^{*}$ & 1.15 & $1.11-1.19$ & $<0.0001$ \\
\hline Grip strength, kgf & $24.1 \pm 5.8$ & $22.5 \pm 5.8^{*}$ & 0.98 & $0.95-1.004$ & 0.1014 & $22.3 \pm 6.0$ & $21.1 \pm 5.7^{*}$ & 0.99 & $0.97-1.02$ & 0.6256 \\
\hline $\begin{array}{l}\text { Quadriceps muscle strength, kgf } \\
\text { (5kgf increase) }\end{array}$ & $27.2 \pm 9.9$ & $23.2 \pm 9.5^{*}$ & 0.84 & $0.78-0.91$ & $<0.0001$ & $26.1 \pm 9.8$ & $22.1 \pm 9.7^{*}$ & 0.85 & $0.79-0.91$ & $<0.0001$ \\
\hline $\begin{array}{l}\text { Weight bearing index, } \mathrm{kg} / \mathrm{kg} \\
(0.1 \mathrm{kgf} / \mathrm{kg} \text { increase) }\end{array}$ & $0.55 \pm 0.20$ & $0.45 \pm 0.18^{*}$ & 0.83 & $0.77-0.90$ & $<0.0001$ & $0.52 \pm 0.19$ & $0.43 \pm 0.19^{*}$ & 0.84 & $0.78-0.91$ & $<0.0001$ \\
\hline $\begin{array}{l}\text { Lower limb muscle mass } / \text { height }^{2} \\
\mathrm{~kg} / \mathrm{m}^{2}\left(0.1 \mathrm{~kg} / \mathrm{m}^{2} \text { increase }\right)\end{array}$ & $2.41 \pm 0.27$ & $2.45 \pm 0.32^{*}$ & 0.95 & $0.89-1.02$ & 0.1421 & $2.38 \pm 0.29$ & $2.44 \pm 0.31^{*}$ & 0.99 & $0.93-1.04$ & 0.6166 \\
\hline
\end{tabular}

${ }^{*} p<0.05$ by non-paired student $t$ test

Adjusted ORs were calculated by multiple logistic regression analysis after adjustment for age, sex, and BMI overall and after adjustment for age and BMI in men and women $B M I$ Body mass index, $m J S W$, Minimum joint space width 


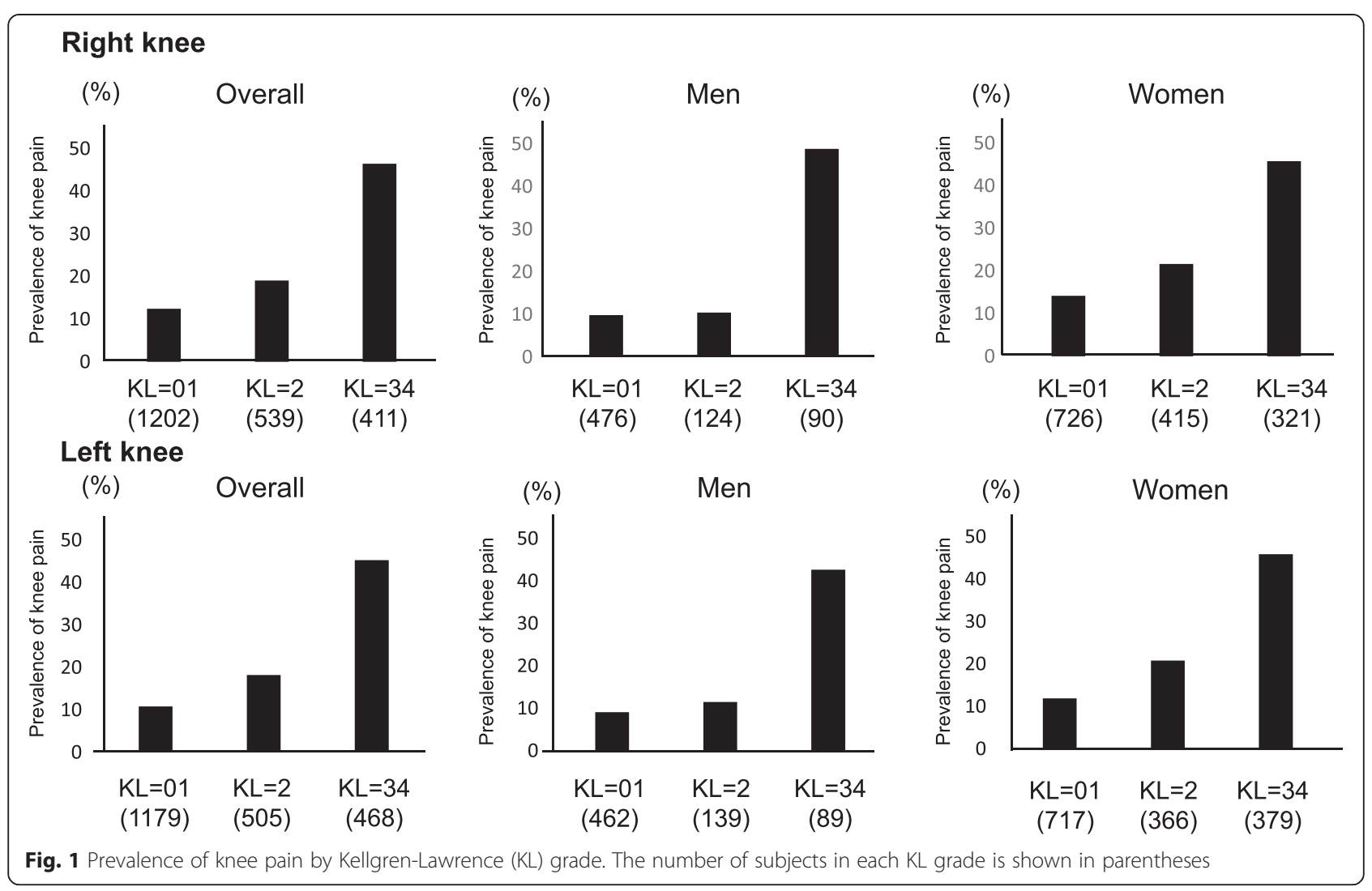

prevalence of knee pain according to WBI and found similar results (Fig. 3).

The threshold values of muscle strength for knee pain were then determined using ROC curve analysis. At the right knee, the threshold values of muscle strength for pain were $27.5 \mathrm{kgf}$ (sensitivity 0.58 , specificity 0.64 , AUC 0.64 ) and $27.0 \mathrm{kgf}$ (sensitivity 0.72 , specificity 0.48 , AUC 0.62 ) in men and women, respectively. At the left knee, the threshold values of muscle strength for pain were 20 kgf (sensitivity 0.39 , specificity 0.82 , AUC 0.64 ) and 23.2 kgf (sensitivity 0.59, specificity 0.41, AUC 0.61) in men and women, respectively. Regarding WBI, the threshold values for pain were $0.43 \mathrm{kgf} / \mathrm{kg}$ (sensitivity 0.57 , specificity 0.69, AUC 0.67) in men and $0.49 \mathrm{kgf} / \mathrm{kg}$ (sensitivity 0.64 , specificity 0.59, AUC 0.64) in women at the right knee, and $0.37 \mathrm{kgf} / \mathrm{kg}$ (sensitivity 0.46 , specificity 0.78 , AUC 0.65 ) in men and $0.40 \mathrm{kgf} / \mathrm{kg}$ (sensitivity 0.49 , specificity 0.74 , AUC 0.64) in women at the left knee.

\section{Discussion}

This is the first study to clarify the effect of quadriceps muscle strength as well as muscle mass on knee pain using a large-scale, population-based, cohort study. In the present study, quadriceps muscle strength was significantly associated with knee pain, while grip strength and muscle mass of the lower limb were not. The significant association of quadriceps muscle strength with knee pain remained after adjustment for age, BMI, gender and knee OA.

The present study first clarified that quadriceps muscle strength and WBI were significantly associated with knee pain even after adjustment for radiographic knee OA, which means that the association of muscle strength with knee pain is independent of radiographic changes. In fact, our previous and other previous studies had already shown that the correlation with radiographic severity of the knee OA was not as strong as one would expect [4,8-10], indicating that there may be some factors other than radiographical changes to explain knee pain. Our results in the present study indicate that not only radiographical changes but also quadriceps muscle strength has an important role in knee pain. The quadriceps muscle is the principal dynamic stabilizer of the knee joint; thus, quadriceps muscle weakness leads to instability of the knee, which may be one of the reasons for knee pain. This also means that knee pain may be prevented by muscle exercise. However, around $10 \%$ of subjects with $\geq 40$ kgf muscle strength had knee pain, indicating that several other factors such as synovitis, knee alignment, meniscal degeneration, thrust and so on may also affect knee pain.

In the present study, although the association of quadriceps muscle strength and grip strength was moderate, 
Table 3 Association of age, BMI, gender, muscle strength and severity of knee OA with knee pain

\begin{tabular}{|c|c|c|c|c|c|c|}
\hline & \multicolumn{3}{|l|}{ Right knee } & \multicolumn{3}{|l|}{ Left knee } \\
\hline & Adjusted OR & $95 \% \mathrm{Cl}$ & $P$ values & Adjusted OR & $95 \% \mathrm{Cl}$ & $P$ values \\
\hline \multicolumn{7}{|l|}{ Overall } \\
\hline Age & 1.01 & $0.996-1.02$ & 0.1698 & 1.00 & $0.99-1.02$ & 0.6107 \\
\hline BMI & 1.09 & $1.06-1.13$ & $<0.0001$ & 1.09 & $1.06-1.13$ & $<0.0001$ \\
\hline Women (vs Men) & 1.34 & $1.03-1.76$ & 0.0299 & 1.35 & $1.03-1.78$ & 0.0321 \\
\hline Quadriceps muscle strength (5kgf increase) & 0.87 & $0.82-0.92$ & $<0.0001$ & 0.88 & $0.82-0.93$ & $<0.0001$ \\
\hline $\mathrm{KL} 2$ & 1.3 & $0.96-1.75$ & 0.0929 & 1.54 & $1.12-2.12$ & 0.0083 \\
\hline $\mathrm{KL} 3$ or 4 & 3.77 & $2.79-5.10$ & $<0.0001$ & 4.49 & $3.31-6.10$ & $<0.0001$ \\
\hline \multicolumn{7}{|l|}{ Men } \\
\hline Age & 1.01 & $0.99-1.04$ & 0.3309 & 1.01 & $0.99-1.04$ & 0.3269 \\
\hline $\mathrm{BMI}$ & 1.09 & $1.02-1.17$ & 0.013 & 1.09 & $1.02-1.18$ & 0.0152 \\
\hline Quadriceps muscle strength (5 kgf increase) & 0.85 & $0.76-0.94$ & 0.0019 & 0.86 & $0.77-0.96$ & 0.0087 \\
\hline $\mathrm{KL} 2$ & 1.06 & $0.54-2.16$ & 0.8753 & 1.18 & $0.60-2.21$ & 0.624 \\
\hline $\mathrm{KL} 3$ or 4 & 5.98 & $3.42-10.54$ & $<0.0001$ & 4.99 & $2.79-8.93$ & $<0.0001$ \\
\hline \multicolumn{7}{|l|}{ Women } \\
\hline Age & 1.01 & $0.99-1.02$ & 0.2416 & 1.00 & $9.99-1.02$ & 0.945 \\
\hline BMI & 1.09 & $1.05-1.14$ & $<0.0001$ & 1.09 & $1.05-1.14$ & $<0.0001$ \\
\hline Quadriceps muscle strength (5 kgf increase) & 0.88 & $0.82-0.95$ & 0.0007 & 0.89 & $0.82-0.96$ & 0.003 \\
\hline $\mathrm{KL} 2$ & 1.33 & $0.95-1.89$ & 0.1007 & 1.67 & $1.15-2.44$ & 0.0068 \\
\hline $\mathrm{KL} 3$ or 4 & 3.24 & $2.28-4.64$ & $<0.0001$ & 3.37 & $3.12-6.44$ & $<0.0001$ \\
\hline
\end{tabular}

Adjusted OR was calculated by multiple logistic regression analysis with age, BMI, gender, Quadriceps muscle strength and KL grade as explanatory variables $O R$ Odds ratio, $C l$ Confidence interval, BMI, Body mass index

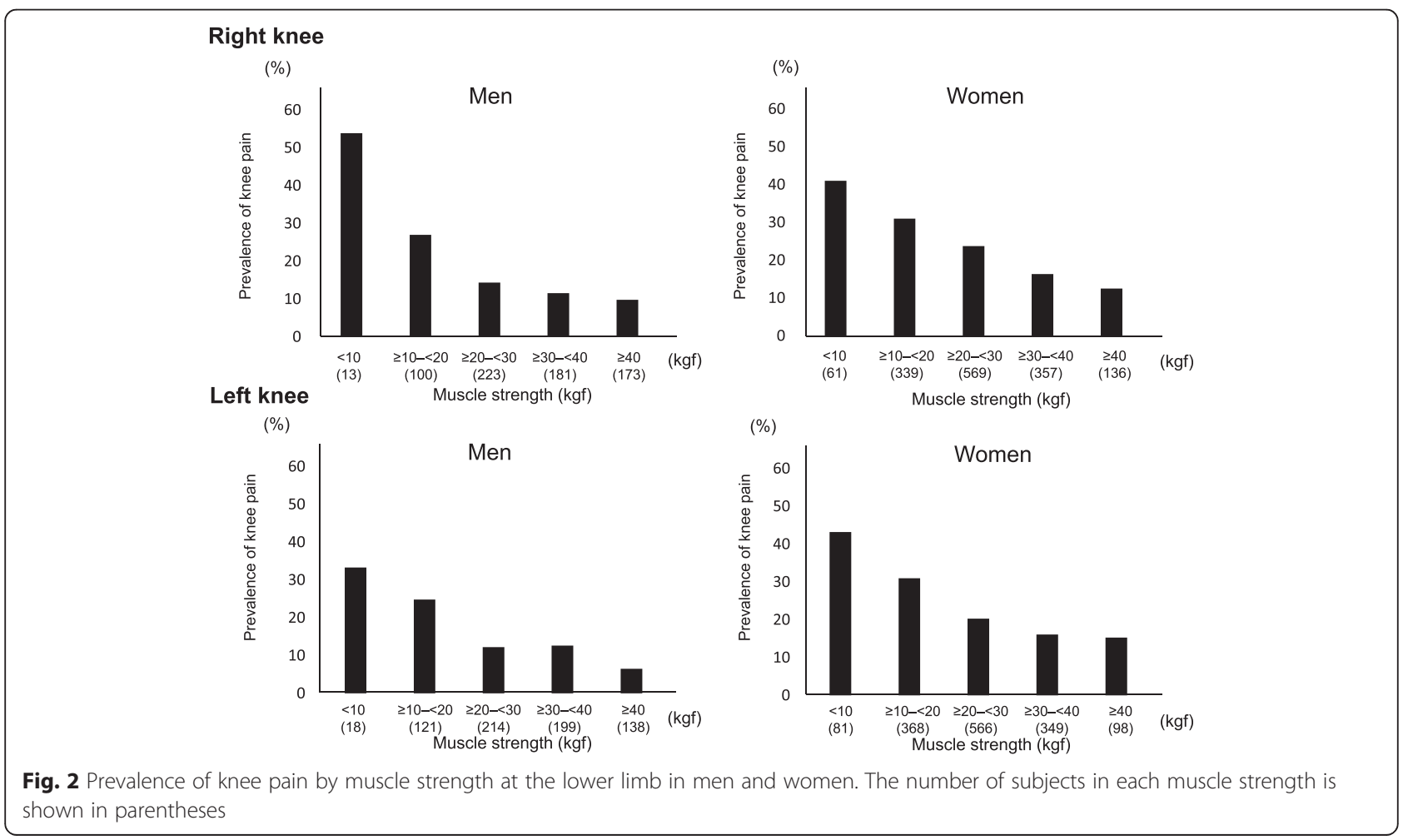


Table 4 Odds ratio for knee pain based on quadriceps muscle strength

\begin{tabular}{|c|c|c|c|c|c|c|}
\hline & \multicolumn{3}{|c|}{ Right knee } & \multicolumn{3}{|c|}{ Left knee } \\
\hline & OR & $95 \% \mathrm{Cl}$ & $P$ value & OR & $95 \% \mathrm{Cl}$ & $P$ value \\
\hline \multicolumn{7}{|l|}{ Men } \\
\hline$<10 \mathrm{kgf}$ & 5.87 & $1.46-23.5$ & 0.0131 & 4.00 & $1.002-15.4$ & 0.0497 \\
\hline$\geq 10-<20 \mathrm{kgf}$ & 2.26 & $1.08-4.83$ & 0.0312 & 3.03 & $1.30-7.59$ & 0.0096 \\
\hline$\geq 20-<30 \mathrm{kgf}$ & 0.95 & $0.48-1.92$ & 0.8909 & 1.39 & $0.61-3.44$ & 0.4405 \\
\hline$\geq 30-<40 \mathrm{kgf}$ & 1.14 & $0.56-2.32$ & 0.7230 & 1.74 & $0.79-4.16$ & 0.1771 \\
\hline$\geq 40 \mathrm{kgf}$ & 1 & & & 1 & & \\
\hline \multicolumn{7}{|l|}{ Women } \\
\hline$<10 \mathrm{kgf}$ & 2.78 & $1.28-6.13$ & 0.0095 & 2.00 & $0.93-4.45$ & 0.0783 \\
\hline$\geq 10-<20 \mathrm{kgf}$ & 1.82 & $1.01-3.42$ & 0.0452 & 1.49 & $0.79-2.94$ & 0.2253 \\
\hline$\geq 20-<30 \mathrm{kgf}$ & 1.7 & $0.98-3.10$ & 0.0612 & 1.03 & $0.56-2.00$ & 0.9227 \\
\hline$\geq 30-<40 \mathrm{kgf}$ & 1.11 & $0.62-2.08$ & 0.7274 & 0.91 & $0.48-1.80$ & 0.7879 \\
\hline$\geq 40 \mathrm{kgf}$ & 1 & & & 1 & & \\
\hline
\end{tabular}

OR Odds ratio, $\mathrm{Cl}$ Confidence interval

quadriceps muscle strength rather than grip strength was significantly associated with knee pain. The QTM used in the present study has higher usability compared with other devices. Thus, to use not only grip strength but also quadriceps muscle strength by the QTM may be recommended to estimate sarcopenia.

In the present study, we also examined muscle mass in the lower limbs and found that the association of muscle mass with quadriceps muscle strength was weak. This may be partly explained by impaired neuromuscular activation, which has an independent contribution to muscle strength after adjustment for muscle mass [29]. Furthermore, several studies reported that greater thigh adiposity is known to be associated with lower strength, worse mobility, and worse lipoprotein profiles in the elderly [30-32], which may obscure the association between muscle strength and mass at the lower limbs. This also may be partly explained by the fact that we examined muscle mass not at the quadriceps but at the whole limb on the right and left sides, because the Body Composition Analyzer MC-190 used in the present study cannot measure only quadriceps muscle mass. The present study also showed that muscle strength rather than muscle mass at the lower limbs was associated with knee pain. Previous studies found that lower limb muscle strength, but not muscle mass, was associated with quality of life [19]. Greater thigh adiposity and impaired neuromuscular function may also obscure the association of muscle mass with knee pain.

In the present study, sex differences were found in the association of quadriceps muscle strength with pain. The OR of muscle strength $<10 \mathrm{kgf}$ for pain was approximately 5 in men compared with muscle strength $\geq 40$ kgf, while it was approximately 2 in women. These discrepancies between the sexes are partly explained by the

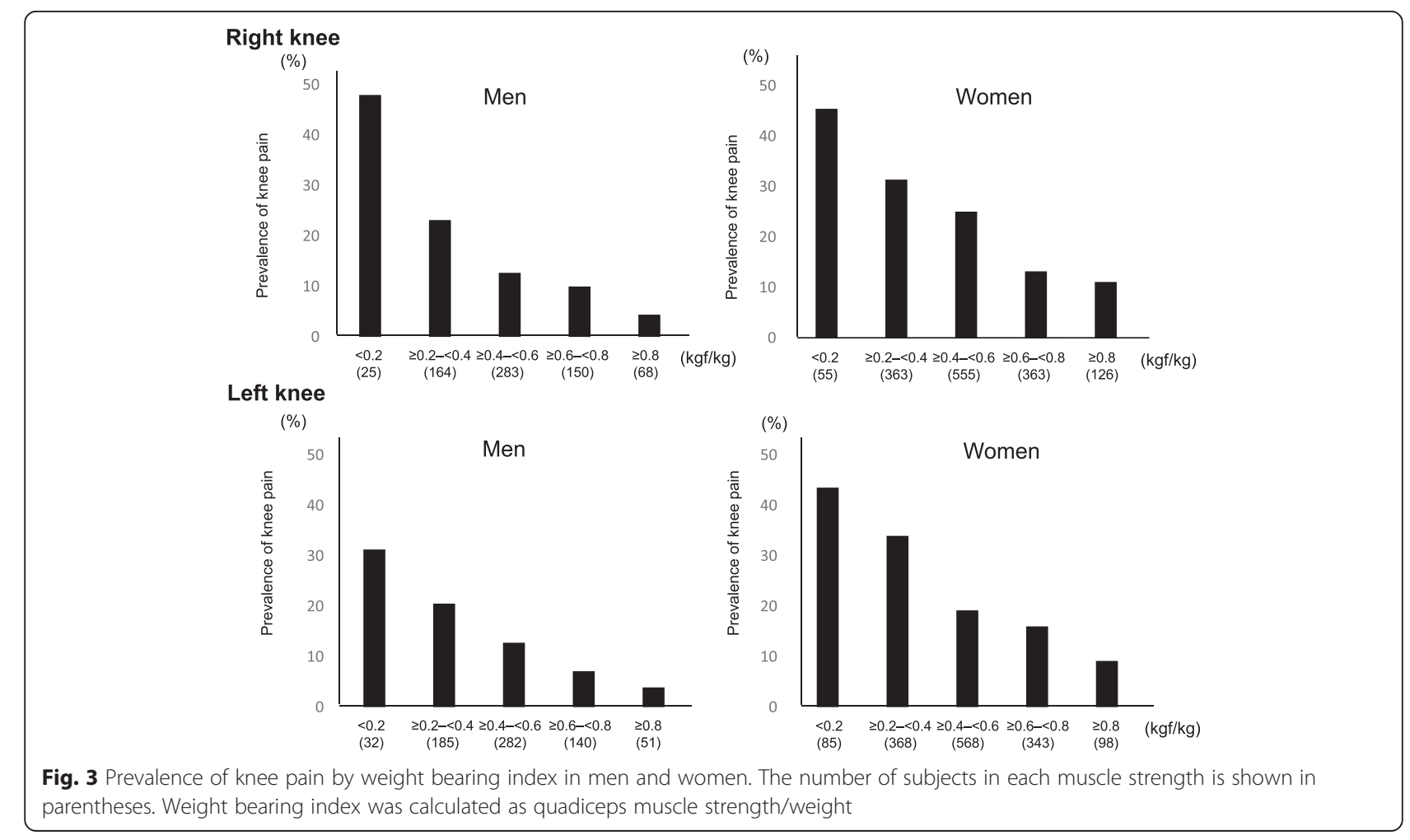


fact that women are more susceptible to pain than men [4]. In fact, our previous study showed that the OR for knee pain in women without radiographic knee OA was greater than that in men without radiographic knee OA [4]. In the present study, the prevalence of knee pain was $6-10 \%$ in men with muscle strength $\geq 40 \mathrm{kgf}$, and $15-16 \%$ in women with muscle strength $\geq 40 \mathrm{kgf}$. This high prevalence of knee pain in women with muscle strength $\geq 40 \mathrm{kgf}$, which is the reference point, may partly explain the lower OR for knee pain in women than men. The threshold of muscle strength for knee pain was similar or higher in women than men, which may indicate that factors associated with knee pain include not only gender but also weaker muscle strength.

There are limitations to the present study. This was a large-scale, population-based, cross-sectional study of baseline data. Thus, causal relationships could not be determined. For example, subjects with knee pain may have less physical activity, thereby leading to muscle atrophy and decreases in strength. Or, those individuals with knee pain may be less likely to perform to maximum capacity on the quadriceps strength assessment. The ROAD study is a longitudinal survey, so further progress may help elucidate any causal relationships. In addition, knee pain due to knee OA may not be rest pain, but mainly motion pain, and we did not classify pain into motion pain and rest pain. Therefore, pain in the present study may include not only that from knee OA but also that from other knee pathology.

\section{Conclusion}

In conclusion, the present cross-sectional study using a large population from the ROAD study showed that quadriceps muscle strength rather than grip strength or muscle mass at the lower limbs was associated with knee pain. After adjustment for knee OA, muscle strength was independently associated with knee pain. The threshold of muscle strength for knee pain was similar in men and women. Further studies, along with continued longitudinal surveys in the ROAD study, will help improve our understanding of the relationship between muscle strength and pain.

\section{Additional file}

\section{Additional file 1: Figure S1. Quadriceps muscle strength by age strata} (PPT $188 \mathrm{~kb}$ )

\section{Competing interests}

The authors declare that they have no competing interests.

\section{Authors' contributions}

SM, TA and NY conceptualized and designed the study, drafted the initial manuscript, and carried out the initial analyses. MY, FT, ST, HK and KN reviewed and revised the manuscript. MT, RK, YA and $\mathrm{HO}$ designed the data collection instruments, and coordinated and supervised data collection, critically reviewed the manuscript. All authors read and approved the final manuscript.

\section{Authors' information}

Not Applicable.

\section{Acknowledgements}

This study was supported by a Grant-in-Aid for H17-Men-eki-009 (Director, KozO Nakamura), H2O-Choujyu-009 (Director, Noriko Yoshimura), H23-Choujyu-002 (Director, Toru Akune), H-25-Choujyu-007 (Director, Noriko Yoshimura), and H25-Nanchitou (Men)-005 (Director, Sakae Tanaka) of the Ministry of Health, Labour and Welfare; and Scientific Research B23390172, B20390182, and Challenging Exploratory Research 24659317 to Noriko Yoshimura; H25-Choujyu004 (Director, Atsushi Harada), H22-Choujyu-Wakate-007 (Director, Shigeyuki Muraki), B23390356, C20591774, and Challenging Exploratory Research 23659580 to Shigeyuki Muraki; Challenging Exploratory Research 24659666 and 21659349 and Young Scientists A18689031 to Hiroyuki Oka; B23390357 and C20591737 to Toru Akune; and Collaborating Research with NSF 0803301100262 (Director, Noriko Yoshimura) from the Ministry of Education, Culture, Sports, Science and Technology in Japan. This study also was supported by grants from the Japan Osteoporosis Society (Noriko Yoshimura, Shigeyuki Muraki, Hiroyuki Oka, and Toru Akune), grants from Mitsui Sumitomo Insurance Welfare Foundation (Shigeyuki Muraki), and research aid from the Japanese Orthopaedic Association (JOA-Subsidized Science Project Research 2006-1 \& 2010-2; Director, Hiroshi Kawaguchi).

The authors thank Dr. Anamizu and members of the Department of Orthopedics; Mr. Kutsuma and other members of the Department of Radiology at Tokyo Metropolitan Geriatric Medical Center. The authors also thank Dr. Takako Nojiri and Mr. Kazuhiro Hatanaka of the Gobo Public Health Centre; Dr. Naoki Hirabayashi of the Kawakami Clinic in Hidakagawa Town; Mrs. Tomoko Takijiri, Mrs. Rie Takiguchi, Mrs. Kyoko Maeda, and other members of the public office in Hidakagawa Town; Dr. Shinji Matsuda of the Shingu Public Health Centre; and Mrs. Tamako Tsutsumi, Mrs. Kanami Maeda, Mrs. Megumi Takino, Mrs. Shuko Okada, Mrs. Kazuyo Setoh, Mrs. Chise Ryouno, Mrs. Miki Shimosaki, Mrs. Chika Yamaguchi, Mrs. Yuki Shimoji, and other members of the public office in Taiji Town for their assistance in locating and scheduling participants for examinations. We also thank Ms. Kyoko Yoshimura, Mrs. Toki Sakurai, Mrs. Saeko Sahara, and Mr. Noriyuki Oe for their assistance in data reduction and administration.

\section{Author details}

${ }^{1}$ Department of Clinical Motor System Medicine, 22nd Century Medical \& Research Center, Faculty of Medicine, the University of Tokyo, Hongo 7-3-1, Bunkyo-ku, Tokyo 113-8655, Japan. ${ }^{2}$ National Rehabilitation Center for Persons with Disabilities, Saitama, Japan. ${ }^{3}$ Department of Orthopaedic Surgery, Wakayama Medical University, Wakayama, Japan. ${ }^{4}$ Department of Orthopaedic Surgery, Tokyo Geriatric Medical Center, Tokyo, Japan.

${ }^{5}$ Department of Orthopaedic Surgery, Faculty of Medicine, the University of Tokyo, Tokyo, Japan. ${ }^{6}$ Department of Medical Research and Management for Musculoskeletal Pain, 22nd Century Medical \& Research Center, Faculty of Medicine, the University of Tokyo, Tokyo, Japan. ${ }^{7}$ Department of Orthopaedic Surgery, Japan Community Health care Organization Tokyo Shinjuku Medical Center, Tokyo, Japan. ${ }^{8}$ Department of Joint Disease Research, 22nd Century Medical \& Research Center, Faculty of Medicine, the University of Tokyo, Tokyo, Japan.

Received: 23 June 2015 Accepted: 24 September 2015

Published online: 16 October 2015

\section{References}

1. Sharma L, Kapoor D. Epidemiology of osteoarthritis. In: Moskowitz RW, Altman RD, Hochberg MC, Buckwalter JA, Goldberg VM, editors. Osteoarthritis: diagnosis and medical/surgical management. 4th ed. Philadelphia: Lippincott Williams \& Wilkins; 2007. p. 3-26.

2. Guccione AA, Felson DT, Anderson JJ, Anthony JM, Zhang Y, Wilson PW, et al. The effects of specific medical conditions on the functional limitations of elders in the Framingham Study. Am J Public Health. 1994;84:351-8.

3. Felson DT, Zhang Y. An update on the epidemiology of knee and hip osteoarthritis with a view to prevention. Arthritis Rheum. 1998;41:1343-55. 
4. Muraki S, Oka H, Akune T, Mabuchi A, En-yo Y, Yoshida M, et al. Prevalence of radiographic knee osteoarthritis and its association with knee pain in the elderly of Japanese population-based cohorts: The ROAD study. Osteoarthritis Cartilage. 2009:17:1137-43.

5. Yoshimura N, Muraki S, Oka H, Mabuchi A, En-yo Y, Yoshida M, et al. Prevalence of knee osteoarthritis, lumbar spondylosis and osteoporosis in Japanese men and women: The Research on Osteoarthritis/osteoporosis Against Disability (ROAD). J Bone Miner Metab. 2009;27:620-8.

6. Ministry of Health, Labour and Welfare. The outline of the results of National Livelihood Survey 2010. Available at http://www.mhlw.go.jp/toukei/saikin/ hw/k-tyosa/k-tyosa10/index.html

7. Linaker $\mathrm{CH}$, Walker-Bone $\mathrm{K}$, Palmer K, Cooper C. Frequency and impact of regional musculoskeletal disorders. Baillieres Clin Rheumatol. 1999:13:197-215.

8. Summers MN, Haley WE, Reveille JD, Alarcon GS. Radiographic assessment and psychologic variables as predictors of pain and functional impairment in osteoarthritis of the knee or hip. Arthritis Rheum. 1988;31:204-9.

9. Cicuttini FM, Baker J, Hart DJ, Spector TD. Association of pain with radiological changes in different compartments and views of the knee joint. Osteoarthritis Cartilage. 1996;4:143-7.

10. Wluka AE, Wolfe R, Stuckey S, Cicuttini FM. How does tibial cartilage volume relate to symptoms in subjects with knee osteoarthritis? Ann Rheum Dis. 2004;63:264-8.

11. Roubenoff R. Sarcopenia: a major modifiable cause of frailty in the elderly. J Nutr Health Aging. 2000:4:4140-2.

12. Sayer AA, Syddall HE, Dennison EM, Martin HJ, Phillips DI, Cooper C, et al. Grip strength and the metabolic syndrome: findings from the Hertfordshire cohort study. QJM. 2007;100:707-13.

13. Bohannon RW. Hand-grip dynamometry predicts future outcomes in aging adults. J Geriatr Phys Ther. 2008;31:313-10.

14. Sirola J, Rikkonen T, Tuppurainen M, Jurvelin JS, Kroger H. Association of grip strength change with menopausal bone loss and related fractures: a population based follow-up study. Calcif Tissue Int. 2006;78:218-26.

15. Kerr A, Syddall HE, Cooper C, Turner GF, Briggs RS, Sayer AA. Does admission grip strength predict length of stay in hospitalised older patients? Age Ageing. 2006;35:82-4

16. Muraki S, Akune T, Oka H, En-yo Y, Yoshida M, Saika A, et al. Association of radiographic and symptomatic knee osteoarthritis with health-related quality of life in a population-based cohort study in Japan. ROAD Stud Osteoarthritis Cartilage. 2010;18:1227-34

17. Wind $A E$, Takken $T$, Helders PJ, Engelbert RH. Is grip strength a predictor for total muscle strength in healthy children, adolescents, and young adults? Eur J Pediatr. 2010;169:281-7.

18. Omori G, Koga Y, Tanaka M, Nawata A, Watanabe H, Narumi K, et al. Quadriceps muscle strength and its relationship to radiographic knee osteoarthritis in Japanese elderly. J Orthop Sci. 2013;18:536-42.

19. Andrews JS, Trupin L, Schmajuk G, Barton J, Margaretten M, Yazdany J, et al. Muscle strength, muscle mass, and physical disability in women with systemic lupus erythematosus. Arthritis Care Res. 2015;67:120-7.

20. Yoshimura N, Muraki S, Oka H, Kawaguchi H, Nakamura K, Akune T. Cohort profile: research on osteoarthritis/osteoporosis against disability study. Int J Epidemiol. 2010;39:988-95.

21. Janssen I, Heymsfield SB, Baumgartner RN, Ross R. Estimation of skeletal muscle mass by bioelectrical impedance analysis. J Appl Physiol. 2000;89:465-71.

22. Kyle UG, Genton L, Slosman DO, Pichard C. Fat-free and fat mass percentiles in 5225 healthy subjects aged 15 to 98 years. Nutrition. 2001;17:534-41.

23. Kyle UG, Genton L, Karsegard L, Slosman DO, Pichard C. Single prediction equation for bioelectrical impedance analysis in adults aged 20-94 years. Nutrition. 2001:17:248-53.

24. Roubenoff R, Baumgartner RN, Harris TB, Dallal GE, Hannan MT, Economos $C D$, et al. Application of bioelectrical impedance analysis to elderly populations. J Gerontol A Biol Sci Med Sci. 1997;52:M129-36.

25. Tanimoto $Y$, Watanabe M, Sun W, Sugiura Y, Tsuda Y, Kimura M, et al. Association between sarcopenia and higher-level functional capacity in daily living in community-dwelling elderly subjects in Japan. Arch Gerontol Geriatr. 2012;55:e9-13.

26. Tanimoto $Y$, Watanabe M, Sun W, Tanimoto $K$, Shishikura $K$, Sugiura $Y$, et al. Association of sarcopenia with functional decline in community-dwelling elderly subjects in Japan. Geriatr Gerontol Int. 2013;13:958-63.
27. Nemoto M, Yabushita N, Kim M, Matsuo T, Seino S, Songee J, et al. Validity of the bioelectrical impedance method for assessing body composition in non-frail and pre-frail older adults. Int J Body Comps Res. 2012;10:55.

28. Kellgren JH, Lawrence JS, editors. The epidemiology of chronic rheumatism: atlas of standard radiographs of arthritis. Oxford: Blackwell Scientific; 1963.

29. Metter EJ, Conwit R, Metter B, Pacheco T, Tobin J. The relationship of peripheral motor nerve conduction velocity to age-associated loss of grip strength. Aging (Milano). 1998;10:471-8.

30. Goodpaster BH, Carlson CL, Visser M, Kelley DE, Scherzinger A, Harris TB, et al. Attenuation of skeletal muscle and strength in the elderly: the health ABC study. J Appl Physiol. 2001;90:2157-65.

31. Visser M, Kritchevsky SB, Goodpaster BH, Newman AB, Nevitt M, Stamm E, et al. Leg muscle mass and composition in relation to lower extremity performance in men and women aged 70 to 79 : the health, aging and body composition study. J Am Geriatr Soc. 2002:50:897-904.

32. Durheim MT, Slentz CA, Bateman LA, Mabe SK, Kraus WE. Relationships between exercise-induced reductions in thigh intermuscular adipose tissue, changes in lipoprotein particle size, and visceral adiposity. Am J Physiol Endocrinol Metab. 2008;295:e407-12.

\section{Submit your next manuscript to BioMed Central and take full advantage of:}

- Convenient online submission

- Thorough peer review

- No space constraints or color figure charges

- Immediate publication on acceptance

- Inclusion in PubMed, CAS, Scopus and Google Scholar

- Research which is freely available for redistribution 